\title{
estudos semióticos
}

\author{
www.fflch.usp.br/dl/semiotica/es
}

\section{Visualização científica us interpretação científica: uma leitura semiótica}

Rozélia de Lourdes Morbach de Medeiros*

\begin{abstract}
Resumo: Propõe-se uma leitura semiótica breve da visualização científica - como atividade científica importante no contexto contemporâneo -, aplicando os conceitos da teoria semiótica de Charles Sanders Peirce, em especial a teoria dos interpretantes. Esta análise visa a uma revisão pertinente da definição de "visualização científica", com o objetivo de entendê-la como uma "interpretação científica", o que representa a renovação daquele conceito que, sob esta denominação, explicita sua fundação semiótica. A pertinência de realizar uma leitura da visualização científica à luz da semiótica de Peirce está relacionada à definição de sua ciência dos signos. Peirce entende o conceito de "signo" como sendo uma relação triádica e esta é a única forma de descrever a manifestação do pensamento e, portanto, aquilo que é expresso na visualização científica. Como atividade científica, a visualização científica é um processo de interpretação, com a finalidade de comunicação. Assim, o artigo detém-se na análise do interpretante, elemento constitutivo da semiose, ou ação do signo, que configura a finalidade e a finalização do signo ou mediação. No processo da semiose, que tem início na representação pelo signo da determinação do objeto Dinâmico, três níveis de interpretantes são gerados, o Imediato, que é a "interpretabilidade" ou o caráter inerente ao próprio signo e que representa exatamente o âmbito de operação específico da visualização científica; o Dinâmico, que é efetivamente o tipo de interpretante gerado em cada interpretação; e o Final, que representa o caráter científico do ideal da interpretação dos signos geradores na visualização científica. Esta análise procura realçar o caráter semiótico próprio da contribuição da visualização científica integrada e no âmbito do ambiente científico e tecnológico contemporâneo.
\end{abstract}

Palavras-chave: visualização científica, Peirce, signo, interpretante

\section{Introdução}

. . um mestre taoista dizia que uma pessoa sábia nunca sente ressentimento ou frustração porque alguém não the disse a verdade; para aquele que sabe ler signos, todos os signos só revelam a verdade.

(Lucia Santaella)

Aqui se farão apenas considerações iniciais sobre a importância de analisar a visualização científica valendo-se de preceitos da semiótica de C. S. Peirce, para lançar algumas hipóteses, que certamente demandarão um estudo mais prolongado, no sentido de dar mais consistência à evolução que esse conceito terá de sofrer para atender o grande desenvolvimento das ciências e tecnologias, que tão bem descreve o mundo contemporâneo.

Desde muito antes de 1987, quando ocorreu a primeira definição do termo visualização científica, que segundo informa Beauclair Seixas ${ }^{1}$, surgiu em 1987 no relatório "Visualization in Scientific Computing", apresentado para a National Science Fundation para sensibilizá-la sobre a importância do uso de métodos de computação gráfica associado às simulações com supercomputadores; as práticas de representação científica compreendiam desde os desenhos de observação dos primeiros naturalistas, já no século XVII, até as modernas técnicas de tomografia computadorizadas, que só vieram a se concretizar depois da década de 80. Nessa medida a aplicação abrangente do termo concordaria com o ponto de vista defendido naquele relatório, pelo qual a visualização científica seria uma

\footnotetext{
* Cognitus. Endereço para correspondência: 〈rozelia@uol.com.br >.

${ }^{1}$ A primeira definição de visualização científica surgiu em 1987 no relatório "Visualization in Scientific Computing", como uma forma de comunicação que transcende as aplicações e os limites tecnológicos. Também nesta época, o termo foi usado para sensibilizar a National Science Fundation para a importância do uso de métodos de computação gráfica associado às simulações com supercomputadores (Roberto de Beauclair Seixas).
} 
forma de comunicação que transcende as aplicações e os limites tecnológicos.

A visualização científica surge então como o termo que nomeia a reunião de processos de computação gráfica, refletindo o momento de incremento do ambiente digital, para em seguida retomar o sentido original, acrescido dessas novas possibilidades tecnológicas de produção de representações, signos ou de um universo maior de linguagem e informação científica.

Isto provoca naturalmente a implementação de um novo olhar sobre o objeto científico, e a possibilidade de outra metodologia científica que como tal se refletem na própria filosofia da ciência. Justamente aí é que os conceitos semióticos, tal como concebidos por Peirce, podem ter um papel determinante na descrição de fundamentos novos, necessários para que a visualização científica enfrente os desafios permanentes que surgem na constante reorganização paradigmática do universo científico.

A visualização científica é legitimamente um sistema semiótico, pois se trata de um ambiente de produção de linguagem e representações. Consequentemente pode ser entendida pela análise da semiótica peirceana. Essa análise tem o objetivo de demonstrar que, com base nos fundamentos dessa semiótica, a visualização científica serviria de recurso importante para o desenvolvimento de novos e melhores métodos de investigação científica. Novos e melhores porque partiriam de pressupostos, bastantes críticos e revolucionários fornecidos pelo "arsenal" filosófico do pensamento peirceano, em relação à Lógica que rege o pensamento científico, ainda vigente nos dias de hoje, muito embora a contestação ao modelo cartesiano se faça a todo o momento, no nível bem concreto das realizações científicas e tecnológicas.

O objetivo maior seria, portanto, pensar a visualização científica no sentido de aprimorá-la como ferramental estratégico de prospecção de novas informações, relações mais precisas de pertinência e verdade entre o objeto real e sua representação em signos, pois é desse modo que ocorre o crescimento e evolução do conhecimento científico.

\section{A visão semiótica em relação à visualização científica}

Há duas colocações primordiais para entendermos uma análise semiótica da visualização científica:

A semiótica peirceana é baseada na noção de signo triádico - do que decorre que todo processo de representação, e de comunicação que é uma designação do primeiro, se dá como uma relação triádica, ou seja, na qual estão implicados três termos, que não são redutiveis, ou desmembráveis em relações diádicas, sob pena de se anular como processo lógico. Essa irredutibilidade é o fator central que diferencia essa definição de signo em relação a outras semióticas.

Essa noção funda uma metodologia científica, gerada por uma filosofia da ciência, cuja matriz ontológica propõe um lugar na análise lógica para os elementos ou dados que se encontram nas fronteiras do impreciso, do espontâneo, do insight, e melhor dizendo dos elementos logicamente indeterminados, a matéria original das descobertas, e que seriam a maioria significativa daqueles que demandam uma visualização científica.

A semiótica é uma ciência filosófica, uma das três ciências normativas (as outras duas são a Estética e a Ética) que integram a Filosofia, além da Fenomenologia e da Metafísica. Essa classificação triádica das ciências coloca a Filosofia no mesmo nível da Matemática e da Ideoscopia, que ele também chama de ciências Especiais. Essas abarcam os dois ramos científicos, as ciências dos eventos físicos e a dos psíquicos, ou seja, as várias semióticas particulares, Física, Química, Biologia, Geologia, Geografia, História, Antropologia, etc.

Todas essas ciências, a Matemática, a Filosofia, em todas as suas designações e a Ideoscopia são ciências da descoberta ou ainda ciências da observação. Descoberta e observação são termos que possuem exatamente o sentido comum dado a eles, muito embora sejam atribuídos aos três tipos de ciências mais abstratas, e cujo nível de generalidade é tal que as torna "capazes de fornecer princípios para as ciências mais particulares" (Santaella, 1983, p. 24). A semiótica geral ocupa, na arquitetura filosófica peirceana, o lugar da Lógica, e como ciência normativa, fornece os princípios lógicos de aplicação universal a cada uma das semióticas, que correspondem às varias ciências especiais.

Cada um destes tipos de ciência, observa e descobre de um modo peculiar. A Matemática monta construções na imaginação segundo preceitos abstratos para realizar descobertas nessa observação, para determinar o que é logicamente possível, fornece a partir disso, preceitos para as demais ciências, inclusive a Fenomenologia e a Lógica. Estas são duas das ciências filosóficas, ou seja, que realizam o tipo de observação própria à Filosofia, que no dizer de Peirce, se limita a descobrir o que é realmente verdadeiro ou ao tanto de verdade que pode ser inferido da experiência comum. Para a filosofia de Peirce, semiótica trata das normas que regem os processos de representação ou de pensamento inteligente.

As ciências especiais exercem a observação e descoberta sobre seus objetos específicos de conhecimento de modo similar entre si, mas diferente das duas primeiras, a Matemática e a Filosofia, porque requerem instrumentos e métodos especiais para que suas observações sejam levadas a efeito, enquanto que estas necessitam basicamente, nesse nível de descoberta, da observação e experimentação de construtos abstratos. 
De qualquer modo, seja a Física ou a História, Geologia ou Geografia todas tem de se reportar aos princípios matemáticos e filosóficos, em especial os lógicos.

Fechando um pouco mais o foco da análise, é preciso colocar que diferente da Linguística, a ciência da linguagem verbal, e que durante muito tempo foi responsável por estabelecer as bases da produção e do uso da linguagem, a semiótica é a ciência de toda e qualquer linguagem. Melhor dizendo é a ciência de todos os sistemas de signos que são os constituintes das linguagens, sendo, portanto mais abrangente que a primeira. Pode-se até mesmo pensar que nela encontra entendimento até formas de representação que se constituiriam como elementos de uma protolinguagem, que muitas vezes é só do que se dispõe nos processos de descoberta científica. Essa consideração é de suma importância para a análise da visualização científica, que tem nos signos visuais sua linguagem principal, e se insere, portanto no âmbito de exame dos modos de fenômenos de produção de significação e de sentido.

Apenas para completar o quadro de classificação das ciências de Peirce há além das ciências da descoberta mais dois tipos de ciência - as ciências de digestão ou revisão (as que digerem e divulgam as descobertas, criando a partir delas uma nova filosofia da ciência) e as ciências aplicadas. As ciências de revisão exercem uma espécie de metalinguagem das ciências da descoberta e as ciências aplicadas são o que o termo mesmo diz, aplicam as descobertas em práticas integradas e tecnologias diversificadas. A Medicina é um bom exemplo disso.
Essa breve digressão sobre a classificação das ciências teve a finalidade de tentar localizar a colocação ou o papel da visualização científica nesse universo. Talvez possa ser compreendida como uma ciência geral aplicada da observação e descoberta, além de digestão e divulgação das descobertas, ou seja, uma espécie de "três em um". Essa quase brincadeira à parte, a visualização científica, e ainda incrementada como um processo de interpretação científica seria uma práxis científica transversal, a ciência observacional per se, a aplicação semiótica especialista, cujo objeto é a produção de representamens científicos.

\section{Visualização científica e a teoria semiótica}

Para a teoria semiótica a visualização científica é um processo de geração de signos interpretantes, signos ou representações, que se inserem num fluxo de tradução de informação em significados, cada vez mais aperfeiçoados na revelação da verdade do objeto científico investigado. Isso pode levar a pensar que uma visualização científica é um processo de interpretação científica, e que o termo visualização transcende a idéia de signos visuais, em direção a descrição mais geral, mais ampla dos processos de significação que incluem os outros sistemas de signos, principalmente os híbridos que tem maior poder de comunicação de idéias, em especial as originais.

Bem, a "interpretação científica" é uma expressão que deriva do conceito de "interpretante" ou o "signo terceiro" da relação semiótica fundamental:

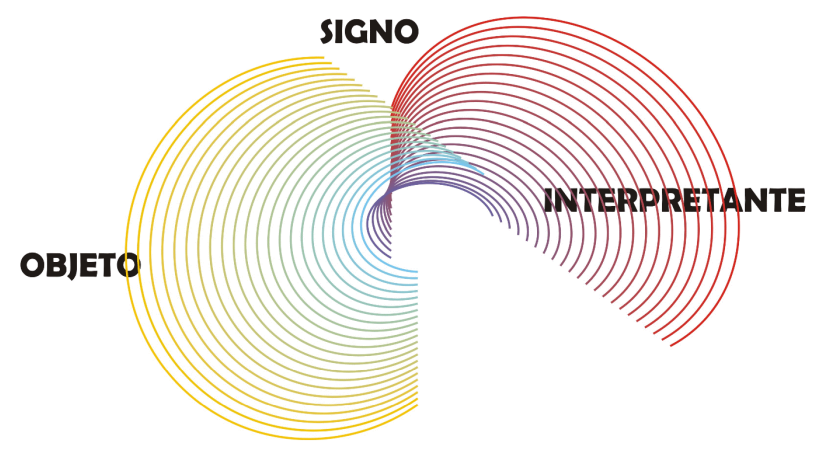

Figura 1: Signo - objeto - interpretante

A relação de representação ou signo é uma relação triádica, entre um signo, um objeto e um Interpretante. Essa relação é irredutível a relações diádicas entre quaisquer dois desses termos. Para haver signo há que haver um objeto que o determina como seu re- presentante, e um Interpretante, mente que, mesmo sendo mera possibilidade, é intérprete desta mediação e determinação.

De certa maneira a noção de Interpretante se confunde com a própria definição de signo, porque um 
Interpretante em si (como é descrito por Peirce) não é mais do que um signo, uma representação do signo que o determina, na mente que o está interpretando. É genuinamente o signo de um outro signo, representa ou traduz na forma de um signo mental, o que o signo, que o determina, como causa imediata, representa do objeto, para a mente que o interpreta.

Um Interpretante não é a mesma coisa que Intérprete ou que Interpretação, pois o Interpretante na semiótica Peirceana é uma propriedade objetiva do signo que a possui, nas palavras de Santaella, "em si mesmo, haja um ato interpretativo particular que o atualize ou não". Já por outro lado, Intérprete é a própria idéia do sujeito particular, portanto agente subjetivo e Interpretação, seria justamente, em tal medida uma atividade subjetiva, exercida por um sujeito. Porém, uma idéia está sempre contida na outra, interpretante, intérprete e interpretação, sugerindo a possibilidade de haver, em termos genuinamente semióticos, graus de passagem entre a instância objetiva e a subjetiva, cujos vetores e direções se alternam, ora convergindo ora divergindo no trânsito da informação entre alteridade e mente. Ainda mais se a mente considerada for uma consciência humana, intérprete Final da visualização científica.

\section{Intérprete (humano, processo cibernético, processo celular) + Ato Interpretativo $=$ Interpretação (cadeia infinita de interpretantes)}

Para se entender o lugar do interpretante na relação sígnica é necessário saber um pouco mais sobre o signo. Existem três naturezas ou fundamentos de signos, duas dimensões de objetos, e três Interpretantes, que correspondem a momentos lógicos na dinâmica da semiose. "Semiose" é o termo utilizado para a ação do signo, ou como define Peirce, aquela ação, própria do signo, de gerar ou produzir e se desenvolver num outro signo, interpretante do primeiro e assim ad infinitum. Para efeitos do que está sendo tratado neste artigo, apenas menciono que os três fundamentos do signo são quali-signo, sin-signo e legi-signo; que os dois objetos são o Dinâmico e o Imediato; de modo a esclarecer melhora classificação dos Interpretantes, que dizem mais diretamente ao nosso tema.

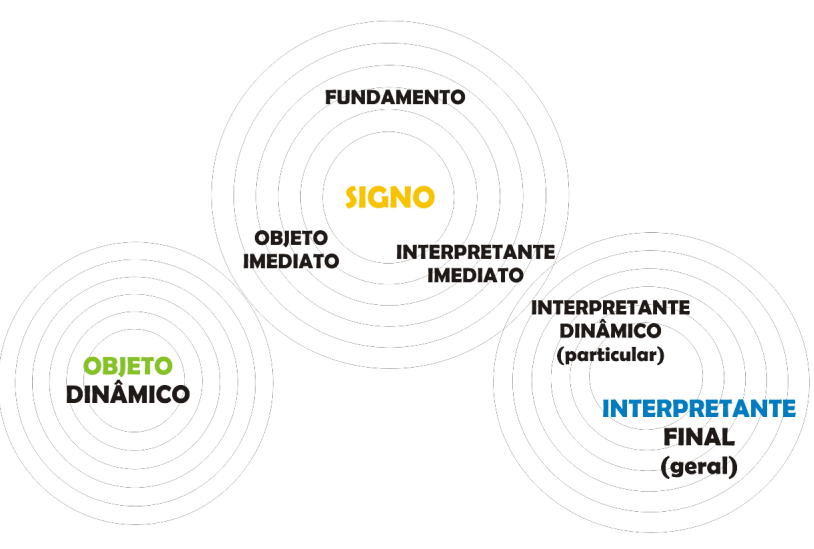

Figura 2: Semiose ou ação do signo

A simples observação desse diagrama acima já permite compreender que o fundamento, o objeto Imediato e o interpretante Imediato são elementos, ou aspectos do signo em si mesmo, enquanto que o objeto
Dinâmico, o interpretante Dinâmico e o interpretante Final, são termos da relação traiádica de representação (significação, interpretação) ou momentos da semiose. 


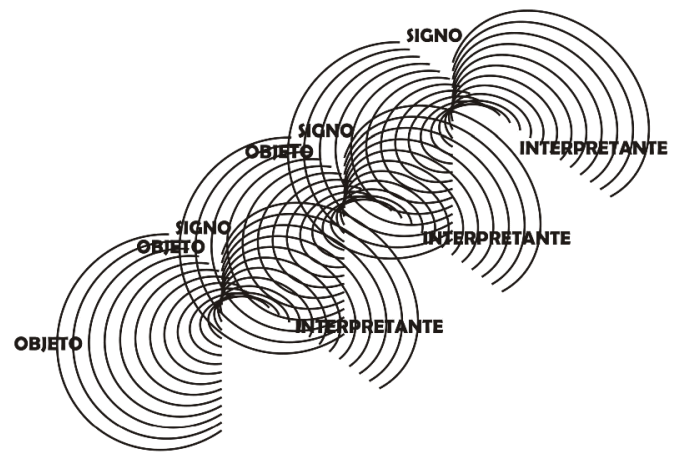

Figura 3: Dinâmica de geração

O modo como um signo é determinado pelo objeto e o modo como representa esse objeto, depende de qual seja o seu fundamento, sua característica, ou das propriedades que o torna capaz disso. Pois, enquanto o signo é o primeiro nessa relação, sua primazia é apenas lógica, sendo que a primazia real pertence ao objeto, o segundo termo, sem o que, ou sem cuja determinação, a relação não se dá. Em relação ao objeto, o signo é uma espécie de voz passiva, já em relação ao interpretante, municiado da força de determinação do objeto, como mediador, gera o interpretante. Quali-signos, por exemplo, só podem ser interpretantes Imediatos de qualidades, ou seja, sua interpretabilidade inerente é a de representar qualidades, seu significado, como mera possibilidade, independente de qualquer ato particular de interpretação. Como está na colocação de Peirce o interpretante Imediato é da natureza de uma impressão (Pierce apud Santaella, 2004, p. 71). É a impressão que o signo causa.

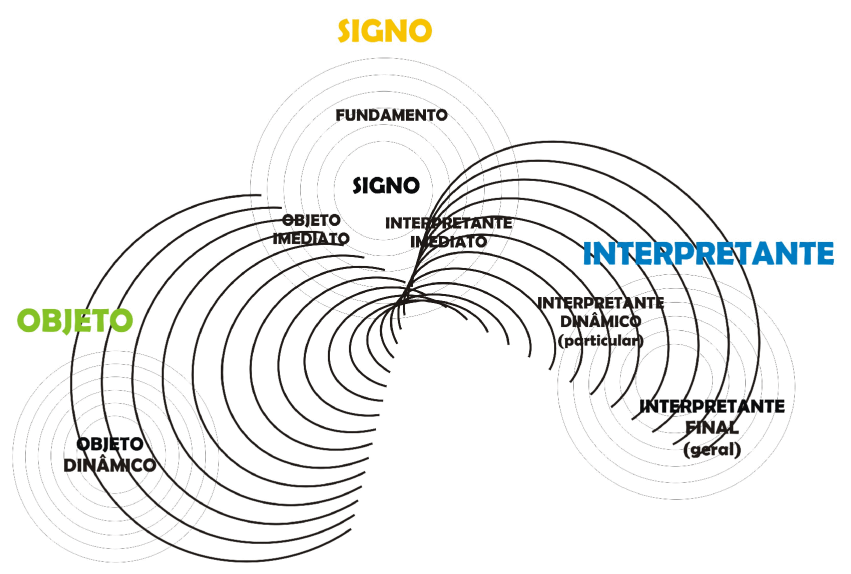

Figura 4: Estrutura e dinâmica do signo triádico

Para que se tenha uma idéia do quadro geral dos interpretantes eles se classificam em termos que se podem dizer morfológicos como três tipos gerais, como aparecem no diagrama acima.

O interpretante Imediato é o primeiro interpretante, aquele que "está implicado no fato de que cada Signo de ter sua interpretabilidade peculiar, antes que ele alcance qualquer intérprete" ou ainda "consiste na Qualidade de impressão que um Signo está apto a produzir, não diz respeito a qualquer rea- ção de fato" (Peirce apud Santaella, p. 71).

O interpretante Dinâmico é "o efeito realmente produzido na mente pelo Signo"' ou "aquilo que é experienciado em cada ato de interpretação e em cada um é diferente daquele de qualquer outro" (Peirce apud Santaella, p. 72-73). Pode-se facilmente depreender que este interpretante é um singular, um segundo na relação triádica, e é o que melhor descreve o caráter da relação do signo com o intérprete, e por isso cujo papel é o mais fácil de compreender na análise de produção 
de linguagem e de comunicação. É o interpretante em sua natureza efetiva.

Interpretante Final é "o resultado final ao qual todo intérprete está destinado a chegar se o Signo for suficientemente considerado" ou o "efeito último que o Signo, na medida em que ele é intencionado ou destinado pelo caráter do Signo, sendo mais ou menos de uma natureza habitual e formal" (Peirce apud Santaella, p. 74). A complexidade dessas definições se deve à precisão lógica a que esta teoria semiótica se propõe a chegar. Porém, por exemplo, ser suficientemente considerado pode ser entendido como o esgotamento exaustivo de geração de interpretantes Dinâmicos para atender a regra contida no interpretante Final, que estabelece o limite lógico a que um signo pode produzir como significado verdadeiro, no caso de semioses científicas.

Para que possamos avançar na análise será necessário recuar a explicação até as origens da formação da teoria semiótica que remonta à fenomenologia concebida por Peirce. Como é peculiar à semiótica peirceana, todas as suas tríades classificatórias são baseadas no seu princípio mais geral que encontrou com o estabelecimento das três categorias fenomenológicas universais, que descreve cada um dos fenômenos no universo fenomenológico total, segundo a proeminência de um desses aspectos. Essas categorias são primeiridade, secundidade e terceiridade.

Estas denominações dadas por Peirce às três categoriais fundamentais do pensamento e da natureza, que é segundo o seu entendimento, as mais universais que se aplicam ao escrutínio de todo o universo fenomênico, resultou de um longo exame sobre o modo como os fenômenos se apresentam à experiência.

Os termos primeiridade, secundidade e terceiridade foram concebidos para ser a denominação mais logicamente pura, e preservar este caráter universal das categorias. A natureza triádica do signo e de toda sua construção metodológica é fundada justamente nestas categorias universais, que os definem sempre com base numa relação entre três elementos, um de primeiridade, um de secundidade e um de terceiridade.

Primeridade - "É o modo de ser daquilo que é tal como é positivamente e sem referência a outra coisa qualquer". "É a categoria do sentimento sem reflexão, da mera possibilidade, da liberdade, do imediato, da qualidade ainda não distinguida, da independência” (C. P. 8.328,1, 302-303, 1.328, 1.531, apud Nöth, p. 65) ${ }^{2}$.

Secundidade - "Começa quando um fenômeno primeiro é relacionado a um segundo qualquer. É a categoria da comparação, da ação, do fato, da realidade e da experiência no tempo e no espaço" (Nöth, 1995, p. 66).

\footnotetext{
2 “C. P." é a abreviação usual para os Collected Papers.
}

Terceiridade - "É a categoria que relaciona um fenômeno segundo a um terceiro. É a categoria da mediação, do hábito, da memória, da continuidade, da síntese, da comunicação, da representação, da semiose e dos signos" (C. P. 1.337, apud Nöth, p. 66).

É também próprio à teoria semiótica, partir do ponto de vista in media res, como é comum chamar no ambiente filosófico, a circunstância em andamento em meio à concreção da realidade. A análise raramente parte do mais simples para o complexo, e sim do mais genuinamente semiótico - que no entendimento peirceano é a natureza fundamental do mundo real, para o mais degenerado, ou seja, mais afastado da natureza plenamente semiótica. Tudo o que é proeminentemente terceiridade é mais compatível com a descrição da análise semiótica, e facilita a compreensão do escopo geral das idéias investigadas.

Tomamos, portanto a visualização científica, como um processo tipicamente semiótico, de geração de interpretantes, e assim também genuinamente de relações de terceiridade.

Seguindo nessa direção temos a análise do interpretante Final como ponto de partida, porque é o terceiro, o tipo mais genuíno de interpretante, ou o interpretante em si, pois que é o interpretante que é já independente do signo que o gerou, constituindo-se num signo mais desenvolvido, ponto de clivagem para nova semiose. Por essas suas características é o que melhor define a relação fundamental de revelação da verdade científica ou realidade do objeto representado, o fenômeno que deu início e determinou as semioses em questão e que se aplica de modo universal a todo o processo descrito como visualização.

\section{Interpretante Final (em si) e a verdade - a relação com o objeto}

Nas semioses científicas, ou seja, quando se está fazendo ciência, o interpretante Final seria sempre a expressão daquilo, ou o significado para o qual o real tende, ou ainda, a verdade que o signo estabelece sobre o objeto real, que é o determinante da semiose. "O Interpretante Final não consiste no modo pelo qual qualquer mente realmente age, mas no modo pelo qual toda mente agiria. Isto é, ele consiste numa verdade que poderia ser expressa numa proposição condicional deste tipo: se tal e tal tivessem de acontecer a qualquer mente, este signo determinaria esta mente a tal e tal conduta. Por conduta quero significar ação sob uma intenção de autocontrole. Nenhum evento que ocorre em qualquer mente, nenhuma ação de qualquer mente pode constituir a verdade dessa proposição condicio- 
nal (C. P. 8.315)".

Dizendo de um modo mais simples, "Final" não quer dizer um fim estático, definitivo, mas no contexto da semiose o limite ideal, aproximável, que apenas indica a tendência da intenção que guia a geração dos interpretantes Dinâmicos. No caso das inferências científicas essa tendência é o desejo da revelação da verdade. Quando se quer visualizar cientificamente, o objetivo é enxergar a verdade dos eventos observados.

Estes caminhos, nos processos de visualização científica, podem ser diversificados, e sua função principal seria justamente enriquecer em possibilidades e alternativas, sem perder de foco a finalidade desses signos - que é dada pelo caráter de seu interpretante Final.

\section{Interpretante Imediato - o escopo inicial da visualização científica}

O fundamento dos signos (que é sua primeiridade) e de seus interpretantes Imediatos (são ao mesmo tempo a terceiridade do signo e a primeiridade do interpretante), que são gerados nos processos de visualização científica, parece ser um fulcro central sobre o que se deve debruçar. As características dos signos, se eles são imagens visuais, diagramas, modelos 3D, ou animações, os capacitam de modo diferenciado a representar seus objetos, com maior o menor propriedade. Como o interpretante Imediato é também interno ao signo, essa interpretabilidade é uma propriedade do signo, o teor daquilo que o signo pode significar, ainda potencial.

A combinação entre as características fundamentais inerentes e dos interpretantes Imediatos dos signos produzidos nas visualizações, que são em conjunto com o objeto Imediato (o modo como o objeto do signo é representado no signo) o resultado na aparência desses signos, se constitui no eixo central da demanda feita a visualização científica, a matéria sobre a qual se deve trabalhar. Tanto melhor será atendida quanto mais precisa for esta combinação.

O esforço na criação de visualizações se concentra justamente no desenvolvimento destas características semióticas - signos cujo fundamento, objeto e interpretante Imediatos sejam competentes para sua função representativa. Representamens apropriados e eficientes para revelar, trazer ao conhecimento o desconhecido.

\section{Interpretante Dinâmico em relação à comunicação}

Considerar os interpretantes Dinâmicos na visualização científica é importante sob o ponto de vista de ser compreendida como um processo de comunicação, de trânsito de informações entre universos ou contexto de compreensão diferente sobre um mesmo assunto, cuja função primordial é mediar essa transferência de conhecimentos.

Do ponto de vista da análise semiótica, há um princípio guia de divisão de interpretante que ilumina de forma esclarecedora como deve ser compreendido o processo fundamental de comunicação. Esse princípio guia que determina qual o lugar ocupado pelo interpretante na comunicação, faz dele três tipos de interpretantes comunicacionais:

- Interpretante intencional - determinação da mente do emissor.

- Interpretante eficiente - determinação da mente do intérprete.

- Interpretante comunicacional (cominterpretant) determinação daquela mente na quais as mentes do emissor e do intérprete tem de se fundir a fim de que qualquer comunicação possa ocorrer.

A determinação da mente do emissor, ou o interpretante intencional, nos processos de visualização científica, necessariamente já refletem o conhecimento que este emissor possui sobre o objeto representado, ou seja, é como a mente do emissor interpreta ou significa a idéia a ser comunicada. É uma relação triádica, semiótica integral.

O mesmo ocorre com relação ao interpretante eficiente, que sendo determinação da mente do intérprete, é o resultado da compreensão, por experiência colateral à do interpretante intencional, do significado do objeto. Esse objeto é sempre de natureza sígnica, pois a sua realidade num processo de comunicação só pode ser a sua representação por um signo. É novamente uma triangulação plena entre mentes e objetos em seus aspectos semióticos.

Por fim, o interpretante comunicacional, ou a determinação daquela mente na quais as mentes do emissor e do intérprete tem de se fundir a fim de que qualquer comunicação possa ocorrer, parece coincidir com a idéia principal que modifica o entendimento que se poderia dar á visualização científica pela teoria semiótica. Justamente aí ocorre o entendimento dado ao processo de comunicação como processo semiótico ou genuinamente triádico, irredutível a relações diádicas, conduz à possibilidade de ter os processos de visualização como integrantes de um método científico semiótico.

A compreensão desse método demandaria um aprofundamento da teoria semiótica de Peirce, até as bases de seu Pragmatismo, impossivel de realizar no escopo desse artigo, porém se pode dizer que todo método científico tem sempre o objetivo de oferecer garantias sobre a revelação da verdade científica. Assim sendo o método pragmático propõe que nesse controle semiótico do pensamento, da evolução das inferências é possivel estabelecer níveis de segurança dado pelo 
próprio signo em sua ação de geração de interpretantes ou semiose.

Fazer ciência é sempre o resultado de uma ação coletiva, porque deverá de algum modo ser a expressão da verdade em alguma linguagem que é de natureza coletiva. A natureza do coletivo é objetiva. Todas as ocorrências e fatores subjetivos, psicológicos presentes e atuantes nas semioses produzidas nas visualizações científicas, para serem tomados como interpretantes científicos têm de passar por operações lógico-objetivas de forma a se tornarem compreensiveis a uma comunidade de mentes. É justamente disso que se trata a função e o objetivo de toda produção de representações, como é o caso da visualização científica.

Nesse sentido o que a teoria do interpretante oferece de inovador é que no seu entendimento a natureza do interpretante, no seu sentido geral, é ser social e coletiva, e sendo assim ele, num processo de comunicação, é por si mesmo uma criatura dessa mente - um cominterpretant, que é a fusão das mentes do emissor e do intérprete, uma Comens (Mente). Todo signo é um ser objetivo, como determinação de seu objeto, mesmo que habitando a subjetividade de uma mente particular. Uma sucessão de interpretantes Dinâmicos (que são signos, não se deve esquecer) ganha nesse percurso em direção sua interpretação final, que é apenas ideal, mais e mais caráter objetivo, pois resulta desse trânsito mediático entre subjetividades, através da mediação de signos.

Estabelecer a diferença entre visualização científica e o que seria uma interpretação científica pode residir no fato de que uma "generalização de ocorrência empírica de interpretação" que nesse processo é aquilo que várias mentes subjetivas, singulares compreendem a partir de uma pluralidade de atos interpretativos sobre determinado objeto, torna-se objetivado num geral, o significado representado num interpretante, um signo triádico.

A evolução deste raciocínio pode levar a conceber a idéia de que a atividade comunicacional e, portanto subjetiva na visualização científica, à luz da teoria semiótica poderia propor uma descrição e um resultado final diferente para esta subjetividade, ou seja, uma garantia da qualidade lógica objetiva e científica dos signos interpretantes produzidos nestes processos. A diferença estaria principalmente no entendimento sobre a natureza do sujeito final (sígnico e objetivo) constituidor, que seria não um intérprete individual, ou mesmo uma interpretação como ato isolado, mas sim uma coleção de atos interpretativos. Esses particulares-subjetivos são tornados coletivo-objetivos em um sistema de signos ou representações científicas, ou seja, de interpretação científica.

\section{Visualização científica no contexto das novas tecnologias e as formas do pensamento}

O desejo de conhecer, a propulsão inequívoca da razão humana em direção ao entendimento tanto da Natureza quanto ao exercício da liberdade da Razão; o sentimento de finalidade na Natureza e na História que segundo Kant é condição a priori da mente humana, faz do animal humano um cientista, antes mesmo de ser um filósofo e um artista. Mais que um desejo de conhecer é uma necessidade objetiva, constituinte da natureza humana. Na dialética transcendental o sentido de finalidade e de ciência se constitui como condição a priori da lógica, na escala do tempo e do espaço na estética transcendental.

Para o contexto da ciência contemporânea a Tecnologia ou os produtos das tecnologias não são apenas resultantes ou efeitos do conhecimento gerado pelas ciências - gerais e aplicadas, da quais derivam diretamente. As tecnologias são igualmente fontes, objetos de ciência, não no sentido meramente instrumental, mas no sentido em que produzem realidade, tecnologias modificam a Natureza, mudam o mundo, e, portanto o objeto da ciência. A visualização científica, que se dá a partir e por meio das tecnologias, trata, opera sobre a realidade, o objeto científico indicialmente representado por seus sistemas de linguagem. O observador modificando o observado e a observação. As tecnologias de comunicação todas confluem para a presença, a presentificação da experiência sensivel, para a realização do virtual, o tempo real, e para o espaço tridimensional, quadri-dimensional. Mas a presença é sempre falseada se ao indeterminado ou ruído, ao acaso original não for reservado o lugar que lhe é de direito, pois esse é o espaço do criativo na mensagem, e da informação (o que se acrescenta) nos processos de comunicação.

Este fator por si só justificaria uma reavaliação do papel ou da envergadura da visualização científica, como atividade científica, à luz da teoria semiótica de C. S. Peirce, que se propõe como base revolucionária para análise de qualquer sistema de signos e, portanto de comunicação.

A visualização científica tem dois destinos preferenciais: a divulgação das descobertas da ciência para o universo leigo de compreensão - a divulgação científica e o destino daquilo que a Natureza e a História (cultura) dizem diretamente ao cientista, que é o responsável especializado para promover o crescimento do conhecimento científico. E, como tentamos apontar nesse artigo a teoria do interpretante de Peirce, que é a base do Pragmatismo - sua teoria epistemológica geral e na sua teoria do método - formal, retórico e me- 
todêutico, poderia promover uma nova compreensão sobre como os métodos da ciência são instrumentados pelos recursos de visualização.

No caso do conceito de interpretação científica, que nasceria do estudo semiótico dos processos de visualização científica, a grande diferença reside no fato de que, para o método semiótico, a formação das primeiras premissas, origem das inferências científicas dos processos de descoberta, e representadas por juízos perceptivos e hipóteses descritivas, signos de mera possibilidade de verdade, são a maioria significativa da representação científica.

Para este esses processos sígnicos, instâncias lógicas peculiares presentes nas descobertas existe na teoria semiótica de Peirce um ferramental analítico extremamente original e poderoso, que não se encontra em outros pensadores, ao menos como uma sistematização filosófica consistente e suficiente para a aplicação numa prática metodológica científica. Isso é o que se pretendeu iniciar ou ao menos exemplificar aqui.

A proposta da interpretação científica como termo alternativo para visualização científica vem como uma renovação do conceito de visualização científica que foi se desenvolvendo e acrescendo de fundamentos, até chegar ao momento quando o termo se consolidou na referência à computação $3 \mathrm{D}$, para rapidamente ficar obsoleto, para descrever a realidade científica e contemporânea, aliás como ocorre em todas as áreas afins do universo tecnológico e é tão típico da dinâmica e da rapidez com que os eventos se sucedem na vida contemporânea. Essa renovação no entendimento de como se inscreve a visualização científica estaria de acordo com a semioticidade que expressa a realidade científica e tecnológica atual, para a qual a leitura semiótica de seus processos parece ser a mais competente.

\section{Referências}

Nöth, Winfried

1995. De Platão a Peirce. São Paulo: Annablume.

Santaella, Lucia

1983. O que é semiótica. São Paulo: Brasiliense. (Coleção Primeiro Passos).

\section{Santaella, Lucia}

2004. A teoria geral dos signos: como as linguagens significam as coisas. São Paulo: Pioneira Thomson Learning. 


\title{
Dados para indexação em língua estrangeira
}

\author{
Medeiros, Rozélia de Lourdes Morbach de \\ Scientific Visualization versus Scientific Interpretation: a Semiotic Reading \\ Estudos Semióticos, vol. 5, n. 2 (2009) \\ ISSN 1980-4016
}

\begin{abstract}
This article is a brief reading of Scientific Visualization, as a very important branch of scientific activities in the contemporary context. It applies some concepts of Charles S. Peirce's semiotic theory. This analysis, specially based on the Interpretants theory, intends to review semiotically the concept of Scientific Visualization, and the possibility to understand it as Scientific Interpretation, an update for that concept, that under this denomination makes explicit its semiotic foundation. The relevance of performing a reading of scientific visualization based on Peirce's semiotics is related to his definition of the science of signs. Peirce understands a sign as a triadic relation and this is the only way to describe the expression of thought and, therefore, what is expressed in scientific visualization. As a scientific activity, Visualization is an interpretation process with a communicative goal. Thus, the article focuses on the analysis of the interpretant, constitutive element of semiosis or sign action, which sets the finality and finalization of the sign or mediation. In the process of semiosis, three levels of Interpretants occurs: the Immediate, the inherent sign interpretability, which represents the very scope of Scientific Visualization; the Dynamic Interpretant, produced in each visualization act, and the Final, which represents the scientific character of Truth Ideal in the signs of Scientific Visualization. This analysis seeks to highlight the peculiar semiotic character of integrated scientific visualization contribution, when it comes to the contemporary scientific and technological environment.
\end{abstract}

Keywords: scientific visualization, Peirce, sign, interpretant

\section{Como citar este artigo}

Medeiros, Rozélia de Lourdes Morbach de. Visualização científica vs interpretação científica: uma leitura semiótica. Estudos Semióticos. [on-line] Disponível em: 〈 http://www.fflch.usp.br/dl/semiotica/es 〉. Editores Responsáveis: Francisco E. S. Merçon e Mariana Luz P. de Barros. Volume 5, Número 2, São Paulo, novembro de 2009, p. 60-69. Acesso em "dia/mês/ano".

Data de recebimento do artigo: 09/12/2008

Data de sua aprovação: 12/03/2009 